\title{
Scattered radiation doses absorbed by technicians at different distances from X-ray exposure: Experiments on prosthesis
}

\author{
Hsien-Wen Chiang ${ }^{\mathrm{a},{ }^{*}}$, Ya-Ling Liu ${ }^{\mathrm{b}, \mathrm{c}}$, Tou-Rong Chen ${ }^{\mathrm{d}}$, Chun-Lon Chen ${ }^{\mathrm{a}}$, Hsien-Jen Chiang ${ }^{\mathrm{a}}$ \\ and Shin-Yu Chao ${ }^{\mathrm{a}}$ \\ ${ }^{a}$ Kaohsiung Chang Gung Memorial Hospital and Chang Gung University College of Medicine, \\ Kaohsiung, Taiwan \\ ${ }^{b}$ Department of Medical Imaging and Radiological Sciences, College of Health Science, Kaohsiung \\ Medical University, Taiwan \\ ${ }^{c}$ Shing-Hou Hospital, Kaohsiung, Taiwan \\ ${ }^{d}$ School of Medical Imaging and Radiological Sciences, Chung Shan Medical University, Taichung, \\ Taiwan
}

\begin{abstract}
This work aimed to investigate the spatial distribution of scattered radiation doses induced by exposure to the portable X-ray, the $\mathrm{C}$-arm machine, and to simulate the radiologist without a shield of lead clothing, radiation doses absorbed by medical staff at $2 \mathrm{~m}$ from the central exposure point. Material and method: With the adoption of the Rando Phantom, several frequently X-rayed body parts were exposed to X-ray radiation, and the scattered radiation doses were measured by ionization chamber dosimeters at various angles from the patient. Assuming that the central point of the X-ray was located at the belly button, five detection points were distributed in the operation room at $1 \mathrm{~m}$ above the ground and $1-2 \mathrm{~m}$ from the central point horizontally. Results: The radiation dose measured at point B was the lowest, and the scattered radiation dose absorbed by the prosthesis from the X-ray's vertical projection was $0.07 \pm 0.03 \mu \mathrm{Gy}$, which was less than the background radiation levels. The Fluke biomedical model 660-5DE $(400 \mathrm{cc}$ ) and 660-3DE $(4 \mathrm{cc})$ ion chambers were used to detect air dose at a distance of approximately two meters from the central point. The AP projection radiation doses at point B was the lowest $(0.07 \pm 0.03 \mu \mathrm{Gy})$ and the radiation doses at point $\mathrm{D}$ was the highest $(0.26 \pm 0.08 \mu \mathrm{Gy})$. Only taking the vertical projection into account, the radiation doses at point $\mathrm{B}$ was the lowest $(0.52 \mu \mathrm{Gy})$, and the radiation doses at point $\mathrm{E}$ was the highest $(4 \mu \mathrm{Gy})$.The PA projection radiation at point $\mathrm{B}$ was the lowest $(0.36 \mu \mathrm{Gy})$ and the radiation doses at point $\mathrm{E}$ was the highest(2.77 $\mu \mathrm{Gy})$, occupying $10-32 \%$ of the maximum doses. The maximum dose in five directions was nine times to the minimum dose. When the PX and the C-arm machine were used, the radiation doses at a distance of $2 \mathrm{~m}$ were attenuated to the background radiation level. The radiologist without a lead shield should stand at point B of patient's feet. Accordingly, teaching materials on radiation safety for radiological interns and clinical technicians were formulated.
\end{abstract}

Keywords: Portable X-ray machine, dose, exposure, ionization chamber dosimeter

\footnotetext{
* Address for correspondence: Hsien-Wen Chiang, Kaohsiung Chang Gung Memorial Hospital and Chang Gung University College of Medicine, Kaohsiung, Taiwan. Tel.: +8867317123-2139; Fax: +8867317123-2523; E-mail: hsienwen30@gmail.com.
}

0959-2989/15/\$35.00 @ 2015 - IOS Press and the authors. 


\section{Introduction}

Medical radiation is commonly used for clinical diagnosis and treatment; however, improper use can result in serious damage to the human body. According to Report No. 160 released by the National Committee on Radiological Protection (NCRP), medical radiation has increased significantly from $15 \%$ in 1982 to $48 \%$ in 2006, in which X-ray examinations represent $5 \%$ and natural radiation represents 50\%. Consequently, the International Commission on Radiological Protection (ICRP) has tightened the guidelines for safe levels of exposure to medical radiation for staff and patients [1]. In Taiwan, the utilization ratio of X-ray examinations was approximately $5.7 \%$ in 2008 [2]. The portable $\mathrm{X}$-ray (PX) and the intraoperative fluoroscopy (C-arm) systems are often used in general wards, intensive-care units, and operating rooms. Access to real-time images can be helpful in the diagnosis and treatment of several acute diseases such as abnormalities of cardiopulmonary function and the chest, emphysema, haemothorax, cardiopulmonary resuscitation, intraoperative catheter positioning in the chest, and live transplantation [3-8]. In 1977, the ICRP enacted three major principles for radiation protection, namely, justification, optimization of protection, and individual dose limitation [9-11]. When using PX devices without lead shielding, staff members often feel concern for their safety. Comparatively, when using X-ray devices in radiation examination rooms, personnel are protected from radiation because of lead shield in or on the walls. Accordingly, an in-depth investigation regarding the effects of spot radiation and scattered radiation at different distances was urgently required.

Generally, detectors for measuring radiation doses include gas detectors, excitation detectors, semiconductor detectors, nuclear-reaction detectors, and chemical dosimeters. In terms of detection of scattered radiation doses, the ionization chamber dosimeter and thermoluminescent dosimeter (TLD) are most commonly used [12]. TLDs cannot measure the radiation dose immediately; i.e., a heating process is required and the luminous signals may disappear during the detection process, leading to the incapability of a duplicate measurement. Therefore, TLDs are most frequently used for detecting monthly-accumulated radiation doses [13]. The ionization chamber dosimeter is inflatable, and when radiation passes through the detector, it is ionized due to the interaction with the gas molecules inside the chamber, and thus electrons and positively charged ions are produced. By measuring these generated electronic pulse signals, the scattered radiation dose in the air can be directly detected.

Previous studies related to ionized radiation doses have mainly focused on the impact when personnel stand at different positions around the patients and on the risk of different cancers induced by radiation exposure. However, investigations on scattered radiation doses at different angles are rarely seen. Trinh, et al. studied whether an incubator could be affected by the radiation from a neighboring incubator at a certain distance. In the experiment, an X-ray source at $160 \mathrm{mAs}$ was vertically projected onto the study area to measure the scattering radiation. The measurement was then used to deduce the scattering radiation in a clinic setting where the regular X-ray output was $2.5 \mathrm{mAs}$. According to the calculation, $125 \mathrm{~cm}$ from the X-ray source, the magnitude of the scattering radiation should become approximately equivalent to that of natural background radiation [14]. With regard to radiation dose detection in medical environments, a fluoroscopic examination on a prosthesis waist using a C-arm perspective X-ray machine in an operating room, researchers used the Rando phantom to simulate effective radiation doses absorbed by different organs with the use of an ionization chamber dosimeter when the exposure factors of X-ray were 91 peak kilovoltage $(\mathrm{kVp})$ and 4.03 milliAmperes $(\mathrm{mA})$ [15]. In the treatment of breast cancer patients using radioactive rays from X-ray machines $(50 \mathrm{kVp})$ during surgery, the scattered radiation dose at $1 \mathrm{~m}$ behind a lead shield was detected using a TLD. The results suggested that the scattered radiation dose behind the lead shield 
was reduced to $1 \%$ of that of the main beam [16]. Conclusively, no research has been conducted on the detection of absorbed doses by patients and the scattered radiation doses at different angles simultaneously. In the present work, with both PX and C-arm perspective X-ray machines taken into account, the scattered radiation doses in the air absorbed by the radiation technicians at different distances were measured. Supposing that the technicians are exposed to radiation in different doses from different distances and angles, the experiments on scattered doses absorbed by prosthesis were conducted in an operating room at Kaohsiung Chang Gung Hospital, Taiwan. During the experiments, the technicians stood behind a lead shield. Using an ionization chamber dosimeter, the scattered radiation doses at different angles and the attenuation tendency of the radiation with distance in the operating room were recorded. Additionally, effective doses absorbed by the patients induced by single radiation exposures were simulated.

\section{Materials and methods}

\subsection{X-ray machines}

The effective radiation dose absorbed by a patient during a single X-ray examination and the scattered radiation dose at $2 \mathrm{~m}$ from the central points were detected and assessed in an operating room at Kaohsiung Chang Gung Hospital, Taiwan. The five body parts that are most commonly examined were selected, and both PX and C-arm perspective X-ray machines were used. For the PX machine, the tube was placed above the prosthesis and an anteroposterior projection (AP projection) was performed. The target angle was $14^{\circ}$ and the thickness of the inherent filter was $2.03 \mathrm{mmAl}$. The chest, abdomen, pelvis, and lumbar vertebrae were illuminated using the PX machine (in which the lumbar vertebrae were horizontally illuminated). The ionization chamber dosimeter for detecting Entrance skin dose (ESD) on the surface of the Rando phantom was placed close to the body and the ionization chamber dosimeters for detecting scattered radiation doses in the air were installed $2 \mathrm{~m}$ from the central exposure point. For the C-arm perspective X-ray machine, the tube was placed below the prosthesis, and a posterioranterior projection (PA projection) was performed, as shown in Figures 1 and 2. The target angle was $16^{\circ}$ and the thickness of the inherent filter was $3 \mathrm{mmAl}$. During the experiments, the liver was transilluminated. The ionization chamber dosimeter for detecting the ESD on the surface of the Rando phantom was placed closely behind the body and the ionization chamber dosimeters for detecting scattered radiation doses in the air were installed at a distance of approximately $1-2 \mathrm{~m}$ from the central point.

\subsection{Ionization chamber dosimeter}

The tube in an ionization chamber is filled with air or the other gases. The metal electrode at the center of the tube is positively charged and the tube wall is negatively charged. When passing through the tube, the ionized radiation will be attracted to the electrons between the central electrode and tube wall, and then move toward the central electrode. These electrons will be converted into electrical signals in the form of pulses and then amplified; and the signal strength is in direct proportion to the radiation intensity in the tube. Accordingly, in a larger ionization chamber, more gases are dissociated and the sensitivity to radiation is higher. In the experiments for this study, two kinds of ionization chambers were used. When detecting the incident ESD on the surface of the Rando Phantom was measured using a fluke biomedical model $660-3 \mathrm{DE}$ dosimeter $4 \mathrm{cc}$ ionizing chamber, the resolution to 


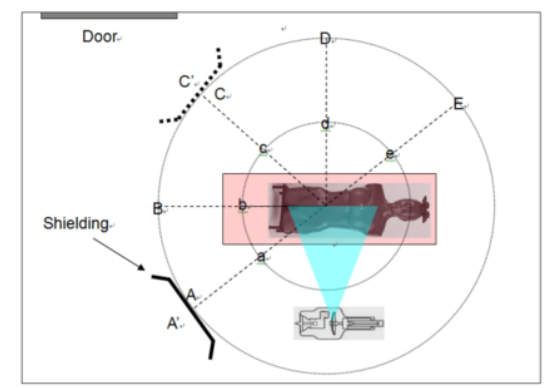

Fig. 1. The $\mathrm{b}$ and $\mathrm{B}$ are located along the phase of the long axis of the body at the distances of 1 to $2 \mathrm{~m}$ from central point (respectively) B is also $1 \mathrm{~m}$ above the ground. A lead plate was placed B and b radiation does measured at each point $\mathrm{C}$ (c) was at $45^{\circ}$ to $\mathrm{C}, \mathrm{D}(\mathrm{d})$ at $90^{\circ}$ to $\mathrm{B}, \mathrm{E}(\mathrm{e})$ at $135^{\circ}$, rad measurement were made at the horizontal.

most sensitive range rate exposure was $10 \mathrm{mR} / \mathrm{min}$, parallel plate ion chamber, $4 \mathrm{~cm}^{3}$ dose equivalent. Comparatively, when detecting scattered radiation was measured using a fluke biomedical model 6605DE dosimeter $400 \mathrm{cc}$ ion chamber perpendiculars to the beam at $2 \mathrm{~m}$ from the phantom side of examination, the resolution to most sensitive range rate exposure was $0.1 \mathrm{mR} / \mathrm{hr}$, parallel plate ion chamber, $400 \mathrm{~cm}^{3}$ dose equivalent. The ionizing chamber is a calibrated chamber that produced current at a certain rate when exposed to a certain level of radiation. The $4 \mathrm{cc}$ (small) chamber produces enough current to discharge the digitizer ( 1 pulse) with every $0.0167 \mathrm{mR}$ of radiation exposure. The $400 \mathrm{cc}$ (large) chamber produces enough current to discharge the digitizer (1 pulse) with every $0.0278 \mu \mathrm{R}$ of radiation exposure. Using these two types of ionization chambers, the energy dependence exhibited similar diagnosis ranges. According to the results of the Taiwan Institute of Nuclear Energy Research, the corrected value of this instrument was 0.5966. In addition, it can also be used to measure space scatter radiation, for example, Radcal electrometer, model 9096 and Victoreen model 451P dosimeter.

\subsection{Rando Phantom}

In the present work, the Random phantom was exposed to X-ray radiation for simulation purposes [17]. The selected prosthesis was female, with a height and weight of $155 \mathrm{~cm}$ and $50 \mathrm{~kg}$, respectively. The prosthesis, without hands or feet and consisting of a human skeleton and soft tissues with densities similar to the human body, was placed on an operating table for exposure to radiation.

\subsection{Experimental data for clinical exposure}

In this study, PX and C-arm perspective X-ray machines were used. The experiments in which different body parts were exposed to X-ray radiation were conducted in an operating room at Kaohsiung Chang Gung Hospital, Taiwan. The levels of radiation doses at different distances and directions were compared. When using the PX machine, the chest, abdomen, and pelvis were examined along the AP direction, and the lumbar vertebrae were examined from the side. The $\mathrm{b}$ and $\mathrm{B}$ are along the phase of the long axis of the body with distances of 1 and $2 \mathrm{~m}$ from central point. $\mathrm{B}$ is also $1 \mathrm{~m}$ above the ground $\mathrm{A}$ lead plate was placed $\mathrm{B}$ and $\mathrm{b}$ radiation does measured at each point $\mathrm{C}(\mathrm{c})$ was at $45^{\circ}$ to $\mathrm{C}, \mathrm{D}(\mathrm{d})$ at $90^{\circ}$ to $\mathrm{B}, \mathrm{E}(\mathrm{e})$ at $135^{\circ}$, radiation measurement were made at the horizontal. Figure 1 shows the distribution of various detection points in the space.

Radiation doses were detected when different X-ray exposure conditions were adopted; specifically 


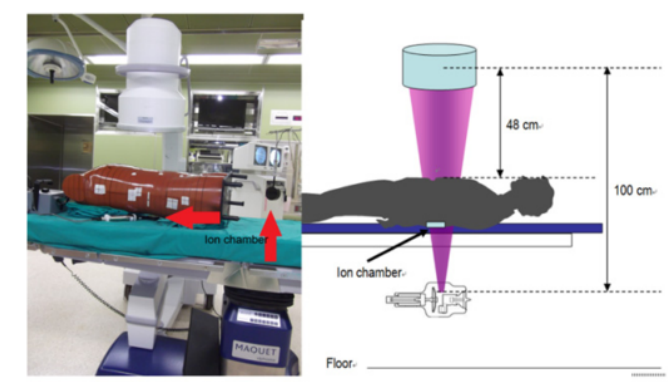

Fig. 2. Assuming that the C-arm X-ray was PA projected onto the prosthesis, an ionization chamber dosimeter was placed below the prosthesis for detecting the entering dose and the other ionization chamber dosimeters were used for detecting the scattering radiation doses. point $\mathrm{A}^{\prime}$ and point $\mathrm{C}^{\prime}$ denote the detecting points behind the lead shield.

X-ray (110 kVp, $32 \mathrm{mAs}), \mathrm{X}$-ray $(115 \mathrm{kVp}, 32 \mathrm{mAs}), \mathrm{X}$-ray $(100 \mathrm{kVp}, 32 \mathrm{mAs})$, and X-ray $(115 \mathrm{kVp}$, $40 \mathrm{mAs}$ ) were applied for examinations of the chest, abdomen, pelvis, and lumbar vertebrae, respectively. These radiation doses are not normally used clinically, since clinical radiation doses are often too low to be effectively detected by a dosimeter. The detection of clinical radiation doses can be quite susceptible to the influences of background radiation. Therefore, the exposure radiation doses were firstly increased and then the clinical radiation doses were deduced (3.2 mAs and $5 \mathrm{mAs})$ based on the detected data. As is generally known, the multiples of $\mathrm{mAs}$ are directly proportional to the radiation dose. When being exposed to radiation, the collimators were all turned on. The distance between the radiation source and body surface ranged from 92 to $94 \mathrm{~cm}$, and the minimum distance where the lumbar vertebrae were illuminated from the side was $60 \mathrm{~cm}$. The distance between the Carm perspective X-ray machine and liver was $48 \mathrm{~cm}$, and the perspective exposure lasted 60 seconds under the exposure conditions of $90 \mathrm{kVp}$ and $3.2 \mathrm{~mA}$. The liver was examined using a PA projection. Figure 2 displays the locating positions of the X-ray tube, detectors, prosthesis, and the ionization chambers for detecting the radiation doses above the body surface.

\subsection{Simulations on the effective doses absorbed by patients}

Using the Monte Carlo method, the effective doses absorbed by patients from X-ray radiation were simulated. The data regarding height, weight, and age of patient were input into the established program PCXMC in the Monte Carlo software for prostheses. The photons with different energies interacted with the prosthesis, and the produced photoelectric scattering, Campton scattering, and coherent scattering were simulated under various geometric conditions.

Combined with the energy spectra generated at different exposure parameters, the radiation doses absorbed by patients were then calculated. The verification of doses exhibited fairly high accuracy [18-20]. Finally, the effective radiation doses absorbed by patients were estimated according to Report No. 103 released by the ICRP.

\section{Results}

The scattering radiation doses at different positions induced by X-ray radiation were simulated. Using the Rando phantom, the radiation doses absorbed by the five body parts and the scattered radiation doses at $2 \mathrm{~m}$ from the central point were detected. For the chest, abdomen, and pelvis, the X- 
rays were projected from front to back. For the lumbar vertebrae, lateral projection was adopted. The above-mentioned body parts were examined by a PX machine. For the liver, a C-arm perspective Xray machine was used and the projection direction was from back to front. Table 1 lists the scattered radiation doses at the points $1-2 \mathrm{~m}$ from the central point. It should be noted that the average indoor background radiation dose in Kaohsiung, Taiwan, is $0.07 \mu \mathrm{Gyh}^{-1}$ [21], and the measured background radiation dose in the operating room is $0.06 \mu \mathrm{Gyh}^{-1}$. With the belly button of the prosthesis as the central point, the detection points were arranged at $2 \mathrm{~m}$ away and $1 \mathrm{~m}$ above the ground at different angles with intervals of $45^{\circ}$. The ratios of scattered radiation doses to the doses absorbed by the prosthesis were calculated and are listed in Table 2. It was observed that the radiation dose detected at point $\mathrm{B}$ was the lowest compared to the doses at the other points, only occupying $21 \%$ of the maximum dose. The scattered radiation doses behind the lead shield were much lower, ranging from 0

Table 1

The ratios of the scattered doses were analyzed at different points at $2 \mathrm{~m}$ from the central point $(1 \mathrm{~m}$ above the ground) to the effective scattered dose Simulated effective doses absorbed by the patient induced by a single X-ray radiation, and the weighting factor according to ICRP Report No. 103.

\begin{tabular}{|c|c|c|c|c|c|c|c|c|c|c|c|c|}
\hline Examination & Tube & $\mathrm{mAs}$ & mAs & ESD & Effective & A & B & C & D & $\mathrm{E}$ & $\mathrm{A}^{\prime}$ & $\mathrm{C}^{\prime}$ \\
\hline & $\begin{array}{l}\text { voltage } \\
\mathrm{kV}\end{array}$ & Study & Clinical & mGy & \begin{tabular}{|l|} 
Dose/mSv \\
ICRP103/60
\end{tabular} & (Air Ke & erma/ uGyl & & & & & \\
\hline AP chest & 110 & 32 & 3.2 & 3.5 & $0.136 / 0.105$ & 0.12 & 0.03 & 0.15 & 0.19 & 0.28 & - & $\begin{array}{l}0.0 \\
1\end{array}$ \\
\hline AP abdomen & 115 & 32 & 5 & 3.4 & $0.174 / 0.187$ & 0.25 & 0.07 & 0.33 & 0.37 & 0.32 & - & $\begin{array}{l}0.0 \\
0\end{array}$ \\
\hline AP pelvis & 100 & 32 & 5 & 3.3 & $0.149 / 0.213$ & 0.17 & 0.11 & 0.23 & 0.21 & 0.16 & - & - \\
\hline Lateral spine & 115 & 40 & 40 & 10.5 & $0.916 / 0.982$ & 4.00 & 0.52 & 0.79 & 3.57 & 1.15 & \begin{tabular}{|l|}
0.0 \\
0
\end{tabular} & - \\
\hline $\begin{array}{lll}\text { PA liver } & \text { C-arm } \\
\text { Fluoroscopy } & \\
2 \mathrm{~m} / 60 \mathrm{sec} & \\
\end{array}$ & 90 & 3.2 & 3.2 & 22.1 & $0.346 / 0.364$ & 1.93 & 0.36 & 2.01 & 2.54 & 2.77 & - & $\begin{array}{l}0.0 \\
1\end{array}$ \\
\hline Air kerma at $1 \mathrm{~m}$ & & & & & & 7.48 & 1.1 & 8.49 & 14.7 & 11.06 & & \\
\hline$\frac{\text { Kerma } 1 m}{\text { Kerma } 2 m}$ & & & & & & 3.86 & 3.03 & 4.22 & 4.34 & 5.32 & & \\
\hline $\begin{array}{l}\text { AP average the } \\
\text { Air kerma at } 2 \mathrm{~m} \#\end{array}$ & & & & & & $\begin{array}{l}0.18 \pm 0 \\
.06 \\
\end{array}$ & $\begin{array}{l}0.07 \pm 0.0 \\
3\end{array}$ & $\begin{array}{l}0.24 \pm 0.0 \\
7\end{array}$ & $\begin{array}{l}0.26 \pm 0.0 \\
8\end{array}$ & $\begin{array}{l}0.25 \pm 0.0 \\
7\end{array}$ & & \\
\hline $\begin{array}{l}\text { Total project Air } \\
\text { kerma at } 2 \mathrm{~m} \#\end{array}$ & & & & & & $\begin{array}{l}1.29 \pm 1 \\
.51 \\
\end{array}$ & \begin{tabular}{|l|}
$0.22 \pm 0.1$ \\
9
\end{tabular} & $\begin{array}{l}0.70 \pm 0.6 \\
9\end{array}$ & $\begin{array}{l}1.38 \pm 1.4 \\
1\end{array}$ & $\begin{array}{l}0.94 \pm 0.9 \\
8\end{array}$ & & \\
\hline
\end{tabular}

Note: $\#=$ mean + standard deviation.

Table 2

The ratios of the scattered doses were analyzed at different points at $2 \mathrm{~m}$ from the central point $(1 \mathrm{~m}$ above the ground) to the ESD absorbed by the prosthesis. The ratios of the scattered doses were induced by projection along different directions.

\begin{tabular}{|c|c|c|c|c|c|c|c|c|}
\hline \multirow[t]{2}{*}{ Kerma } & \multirow[t]{2}{*}{ Projection } & \multirow{2}{*}{\begin{tabular}{|l|} 
ESD \\
$(m G y)$
\end{tabular}} & \multicolumn{5}{|c|}{ Spatial absorbed dose $\left(\times 10^{-4}\right)$} & \multirow[t]{2}{*}{ Average } \\
\hline & & & A & $\mathrm{B}$ & $\mathrm{C}$ & $\mathrm{D}$ & E & \\
\hline Chest & AP & 1 & 0.34 & 0.09 & 0.43 & 0.54 & 0.79 & \multirow[t]{3}{*}{0.58} \\
\hline Abdomen & $\mathrm{AP}$ & 1 & 0.73 & 0.20 & 0.96 & 1.08 & 0.93 & \\
\hline Pelvis & AP & 1 & 0.52 & 0.33 & 0.70 & 0.64 & 0.48 & \\
\hline L-Spine & Left Lat & 1 & 3.81 & 0.50 & 0.75 & 3.40 & 1.10 & 1.91 \\
\hline Liver (C-arm) /60s & PA & 1 & 0.88 & 0.16 & 0.91 & 1.15 & 1.26 & 0.87 \\
\hline Average & & & $1.25 \pm 1.29$ & $0.26 \pm 0.14$ & $0.75 \pm 0.19$ & $1.36 \pm 1.05$ & $0.91 \pm 0.27$ & \\
\hline
\end{tabular}


to $0.01 \mu \mathrm{Gy}$, suggesting that the lead shield played a critical role in shielding the X-ray radiation.

\section{Discussion}

According to the limits of exposure radiation for personnel mandated by the ICRP, the effective radiation dose should not exceed $100 \mathrm{mSv}$ in five years and the effective dose in a single year should not exceed $50 \mathrm{mSv}$ [22-24]. In operating room, it was to simulate space exposure doses, measuring at a distance of $2 \mathrm{~m}$ from the tube and the radiation doses behind the lead barrier. It was assumed that an operator in a radiologist makes operating room and ward exposures per year with the Nomad (50 exposures per day, 5 days per week, 50 weeks per year). Using the conversion factor from Gy to $\mathrm{Sv}$ $\left(1.14 \mathrm{SvGy}^{-1}\right)$ [25]. Table 1 lists the simulation results of scattered radiation doses absorbed by a radiologist without a shield of lead clothing within a range of $2 \mathrm{~m}$. During the experiments, the technician was exposed to 12 PX examinations on the chest, 5 PX examinations on the abdomen, 3 PX examinations on the pelvis, $8 \mathrm{PX}$ examinations on the lumbar vertebrae, and $\mathrm{C}$-arm perspective PX examination for 1 minute in the operating room. To calibrate the conversion, the radiologist in the operating room ,the prediction value of the yearly effective stimulating doses at A, B, C, D, E, C, and the occupational yearly dose limit are $10.58 \mathrm{mSv}(21 \%), 1.58 \mathrm{mSv}(3 \%), 3.55 \mathrm{mSv}(7 \%), 10.22 \mathrm{mSv}$ (20\%), $4.94 \mathrm{mSv}(10 \%), 0.03 \mathrm{mSv}$. The yearly effective stimulating radiation doses of the radiologist in the ward at A, B, C, D, E, C are $1.58 \mathrm{mSv}(3 \%), 0.40 \mathrm{mSv}(1 \%), 2 \mathrm{mSv}(4 \%), 2.47 \mathrm{mSv}(5 \%), 3.28$ $\mathrm{mSv}(7 \%), 0.10 \mathrm{mSv}$, are below the yearly dose limit of $50 \mathrm{mSv}$. Using this method, the estimated radiologist were operating room and ward $\mathrm{C}$ point annual dose to an operator is 0.03 and $0.1 \mathrm{mSv} \mathrm{y}^{-1}$ if the backscatter shield is in place and 3.55 and $2 \mathrm{mSv} \mathrm{y}^{-1}$ if the backscatter shield is not used. It is appropriately safe to lye behind the lead barrier, the occupational dose limit is $1 \sim 21 \%$. These differences were quite pronounced. The results indicated that the scattered radiation from X-rays exhibited a directional distribution, and the position where the technician stood affected the absorbed scattered radiation doses. As suggested by previous studies, the scattered radiation induced by X-ray exposure at a distance of $2 \mathrm{~m}$ was attenuated to background radiation levels (U.S. $=8.493 \mu \mathrm{Gy}$ per day) [26]. In the operating room, the measured background radiation dose was $0.06 \mu \mathrm{Gyh}^{-1}$, i.e., the dose was $1.44 \mu$ Gy per day. As shown in Table 1, except for the X-ray examinations on the lumbar vertebrae and the perspective X-ray, the induced radiation was attenuated to background radiation levels. According to the provisions relevant to radiation safety, technicians should use portable lead shields when the patient stands within a range of 1 foot for the purpose of protecting the other patients and medical staff from unnecessary exposure and to reduce the radiation doses at work [26-28]. In this study, the experimental data provide professional knowledge on clinical radiation exposure levels for nurses in hospitals. Table 1 illustrates the ratios of radiation to distance during examinations using a $\mathrm{C}$-arm perspective machine, from which it was concluded that the scattered radiation was inversely proportional to the distance from the central point. Given an intensive care unit (ICU) in which 12 patients were included, the scattered radiation absorbed by the nurses for daily routine care who stood $3 \mathrm{~m}$ from the central point of the X-ray source was attenuated to the daily background radiation value, $1.44 \mu \mathrm{Gy}$. Additionally, for patients at more than $2 \mathrm{~m}$ from the patient to be X-ray examined, the absorbed scattered radiation was attenuated to $0.19 \mu \mathrm{Gy}$, which is far below the daily background radiation value. In other words, the scattered radiation absorbed by the nurses and other patients in an ICU was almost equal to background radiation levels. With regards to the spatial distribution of radiation doses, although the detecting points in this study weren't densely distributed, it was observed that the radiation doses were characterized by apparent directivity. As shown in Table 2, the radiation 
dose measured at point B was the lowest, being approximately $21 \%$ of the doses at the other points. In the experimental results for perspective X-ray examination, similar results were also acquired, i.e., the radiation dose at point $\mathrm{B}$ was the minimum. The heel effect may account for these phenomena. Generally, the target angle of an X-ray tube ranges from $5^{\circ}$ to $15^{\circ}$ [21]. Due to varying target angles of the anode, X-rays pass through coolant oils and bearings and thus the energy is attenuated from the obstacle of the cooling device. Most X-rays are moved toward the cathode end, leading to comparatively stronger X-ray intensities near the cathode end and uneven energy distributions. As such, X-ray tubes with different target angles can give rise to different energy heel effects and different scattered radiation doses at different positions in a space. When both the portable and $\mathrm{C}$-arm perspective X-ray machines were used, the scattered radiation doses at $1 \mathrm{~m}$ above the ground from the $\mathrm{X}$-ray projection along different directions were measured and are listed in Table 2. In descending order, the radiation induced by X-ray projection from the top (ceiling) to bottom (ground) was the highest, followed by the radiation induced by projection from the left side of body, and finally, the radiation by projection from bottom to top was the lowest. The ratio of radiation doses under these three conditions was 5:2:1.

The measuring doses at a distance of $2 \mathrm{~m}$, Chet was the lowest dose of $0.03 \mu \mathrm{Gy}$ at point $\mathrm{B}$, and the highest dose of $0.28 \mu \mathrm{Gy}$ at point E. Abdomen was the lowest dose of $0.07 \mu \mathrm{Gy}$ at point $\mathrm{B}$, and the highest dose of $0.37 \mu \mathrm{Gy}$ at point $\mathrm{D}$. Pelvis was the lowest dose of $0.11 \mu \mathrm{Gy}$ at point $\mathrm{B}$, and the highest dose of $0.23 \mu \mathrm{Gy}$ at point $\mathrm{C}$. Lateral spine was the lowest dose of $0.52 \mu \mathrm{Gy}$ at point $\mathrm{B}$, and the highest dose of $4 \mu \mathrm{Gy}$ at point $\mathrm{A}$. Liver fluoroscopy was the lowest dose of $0.36 \mu \mathrm{Gy}$ at point $\mathrm{B}$, and the highest dose of $2.77 \mu \mathrm{Gy}$ at point $\mathrm{E}$.

From the following attenuation formula:

$$
N=B N_{o} e^{-u L}
$$

$\mathrm{N}$ is the number of radiation passing through length of $\mathrm{L}, \mathrm{B}$ is the build-up factor, No is the number of the initial radiation, $\mathrm{u}$ is the linear attenuation coefficient of the anode. $\mathrm{L}$ is the distance of radiation passing through it. When $\mathrm{L}$ is higher, the number of $\mathrm{N}$ is smaller. The longer of the passing through distance, and the strength attenuation of x-rays is smaller. The measured highest value at different positions is the nearest the location of the central exposure point. The main reason to the highest dose in Lateral spine at point $\mathrm{A}$ is the causing of the back scattering effect. In according with different checking parts, it is discovered that the value of the space absorbed dose is smaller when the distance is farer from the central beam of $\mathrm{x}$-rays. In addition, the doses are the lowest from the direction of the head to the feet of the patient, is approximately $21 \%$ of other different points. So, to the radiologist, the point is the most appropriate position when taking an exposure. It is reported by ICRP 103 and ICRP 60, the one-time effective dose of the patient, the weighting factor of the reproductive gland tissue is substantially lower. The altering of calculating mode, the value of the risk factor of the stochastic effect is 0.2 by ICRP 60 in 1990, which is below to 0.08 by ICRP 103 in 2007. The tissue weighting factor of the mammary gland is elevating substantially from 0.05 in 1990 to 0.12 in 2007 . So, the calculation mode revised by ICRP 103 and ICRP 60, using portable X-ray (PX) and fluoroscopy (C-arm), the one-time effective doses of the abdomen are $0.174 \mathrm{mSv}$, and the specific value of the both is appropriately 1.07 times. The specific value of the abdomen of the liver fluoroscopy is 1.05 times. Because of the angle diversity of the both x-rays tubes, the target angle of the portable is 14 degrees, the target angle of the movable fluoroscopy x-rays is 16 degrees, so it is to cause to the disparity to the effective dose of the both. 
PX machines can be quite convenient for rapid diagnoses. However, radiation exposure is a sensitive topic among medical personnel. Fortunately, according to the present results, when using PX machines for examinations, the scattered radiation at $2 \mathrm{~m}$ from the central exposure point is attenuated to background radiation levels. Additionally, since radiological technicians wear lead clothing during exposure, they need not be concerned. In the present work, the experiments were conducted on a prosthesis in an operating room, and the scattered radiation doses from exposure in real situations were simulated. The data of scattered radiation attenuation in a space when being exposed to PX machines were established, which will enrich professional knowledge of radiation safety for clinical radiological technicians and provide useful data for radiological students.

\section{Conclusions}

In this study, with the adoption of the Rando Phantom, scattered radiation doses in an operating room were detected using ionization chamber dosimeters. During the experiments, the X-ray was projected along three directions, vertical AP, vertical PA, and laterally from left to right, and the distributions of scattered radiation induced by X-ray exposure were simulated. The results suggested that the scattered radiation in the space were directional; specifically, the radiation dose near the cathode end was greater, and the scattered radiation decreased as the distance increased from the central radiation source. The scattered radiation dose data at different points in the space induced by portable and $\mathrm{C}$-arm perspective $\mathrm{X}$-ray examinations in the radiological department at Kaohsiung Chang Gung Hospital in Taiwan were obtained, which will increase the clinical teaching materials for radiological technicians and interns. The results of this study have been selected as training material on radiation safety for medical staff at this hospital.

\section{Acknowledgments}

This study was supported by the Chang Gung Memorial Hospital, Taiwan and a Chang Gung Hospital Institutional Review Board, Taiwan approval has been obtained (100-2249B).

\section{References}

[1] National Council on Radiation Protection and Measurements, NCRP Report No. 160 Pie Charts, Available at: http://www.ncrponline.org/Publications/160 Pie charts.html, last accessed: Nov 18th, 2009.

[2] C.J. Tung, et al., Population dose from medical diagnostic exposure in Taiwan, Radiation Protection Dosimetry 146 (2011), 248-251.

[3] Ganapathy, N.K. Adhikari, J. Spiegelman and D.C. Scales, Routine chest x-rays in intensive care units: A systematic review and meta-analysis, Crit Care 16 (2012), R68.

[4] J.T. McCormick, M.S. O'Mara, P.K. Papasavas, et al., The use of routine chest x-ray films after chest tube removal in postoperative cardiac patients, The Annals of Thoracic Surgery 74 (2002), 2161-2164.

[5] C.L. Chen, The right posterior sector graft in living donor liver transplantation revisited, Liver Transplantation 20 (2014), 1019-1020.

[6] H. -W. Chiang, et al., Application of a computer-assisted system to calculate liver volumetry in living donor liver transplantation, International Journal of Advancements in Computing Technology 4 (2012), 242-249.

[7] Asrani, R. Kaewlai, S. Digumarthy, M. Gilman and J.A. Shepard, Urgent findings on portable chest radiography: What the radiologist should know-review, American Journal of Roentgenology 196 (2011), s45-61.

[8] Marleen E. Graat, et al., The clinical value of daily-routine chest radiographs in a mixed medical-surgical intensive care 
unit is low, Crit Care 10 (2006), R11.

[9] R.C. Thompson and S.J. Cullom, Issues regarding radiation dosage of cardiac nuclear and radiography procedures, Journal of Nuclear Cardiology 13 (2006), 19-23.

[10] United National Scientific Committee on the Effects of Atomic Radiation, UNSCEAR 2000 Report to the General Assembly with Scientific Annexes Sources New York 1 (2000), 82-94.

[11]E.W. Charles and L.S. Thomas, The alara concept in pediatric CR and DR: Dose reduction in pediatric radiographic exams-A white paper conference, American Journal of Roentgenology 184 (2005), 373-374.

[12] Y.S. Tyan, et al., The effective dose assessment of C-arm CT in hepatic arterial embolisation therapy, The British Journal of Radiology 86 (2013), 1024.

[13]H.E. Johns, Physics of Radiology, 4th ed., Charles River Media, Hingham, MA, 1983.

[14] Angela M. Schoenfeld Trinh, Alan H. Levin and L. Terry, Scatter radiation from chest radiographs: Is there a risk to infants in a typical NICU? Pediatric Radiology 40 (2010), 704-707.

[15] K.I.M. Sangroh, et al., Kerma area product method for effective dose estimation during lumbar epidural steroid injection procedures: Phantom study, American Journal of Roentgenology 192 (2009), 1726-1730.

[16] D.J. Eaton, et al., Radiation protection for an intra-operative X-ray device, Radiation Protection 84 (2011), 1007.

[17]P.C. Shrimpton, B.F. Wall and E.S. Fisher, The tissue-equivalence of the Alderson Rando anthropomorphic phantom for X-rays of diagnostic qualities, Physics in Medicine and Biology 26 (1981), 133-139.

[18] Servomaa and M. Tapiovaara, Organ dose calculation in medical X ray examinations by the program PCXMC, Radiation Protection Dosimetry 80 (1998), 213-219.

[19] N. Khelassi-Toutaoui, Y. Berkani, V. Tsapaki, et al., Experimental evaluation of PCXMC and PREPARE codes used in conventional radiology, Radiation Protection Dosimetry 131 (2008), 374-378.

[20] Kruger Randell, et al., Effective dose assessment for participants in the national lung screening trial undergoing posteroanterior chest radiographic examinations, American Journal of Roentgenology 201 (2013), 142.

[21]P.H. Lin, C.J. Chen and Y.M. Lin, Assessment of dose equivalent to Taiwan population from natural background radiation, Nuclear Science Journal 28 (1991), 467-470.

[22] S.C. Bushong, Radiologic Science for Technologists-Physics, Biology and Protection, 10th ed., Mosby, St Louis, 2012, pp. 114-120.

[23] National Research Council, Health risks from exposure to low levels of ionizing radiation: BEIR VII phase 2, National Academies Press, Washington DC, 2006, p. 424

[24] The 2007 recommendations of the International Commission on Radiological Protection: ICRP publication 103, Annals of the International Commission on Radiological Protection 37 (2007), 1-332.

[25] P.H.G. Rosado, M.S. Nogueira, F. Genezini and E.C. Vilela, Measurement of conversion coefficients between free in air kerma and personal dose equivalent for diagnostic X-ray beams, Radiation Measurements 43 (2008), 968-971.

[26] J.M. Cupitt, S. Vinavagam and I. McConachie, Radiation exposure of nurses on an intensive care unit, Anaesthesia 56 (2001), 183.

[27] M.N. Sabau, M.A. Radkowski and C.J. Vyborny, Radiation exposure due to scatter in neonatal radiographic procedures, American Journal of Roentgenology 144 (1985), 811-814.

[28] Radiation Protection in Pediatric Radiology, In: NCRP Report No. 68, National council on radiation protection and measurements, Washington DC, 1981, Available at: www.ncrppublications.org. 